\title{
A contribuição da Ontopsicologia para a compreensão do conhecimento humano: estudo dos conceitos de importantes estudiosos do período do Renascimento ao Empirismo ${ }^{1}$
}

\author{
Adalberto Panzan Junior ${ }^{2}$
}

Resumo: Ao se debruçar sobre as obras, os ensinamentos, as divergências e as novidades trazidas pelos grandes expoentes do Humanismo, agora no período compreendido do Renascimento ao Empirismo, não se pode ainda presumir compreender a evolução do conhecimento, e nesse sentido, também do ser humano, sem considerar a novidade da Ontopsicologia. $\mathrm{O}$ objetivo geral deste artigo é relembrar, dentro de um período histórico singular, novas passagens da evolução do conhecimento humano e confrontá-las com o pensamento de Antonio Meneghetti acerca de cada uma, demonstrando a necessidade da compreensão ontopsicológica dos argumentos apresentados.

Palavras-chave: Ontopsicologia; Filosofia; Humanismo; Renascimento; Empirismo.

\section{The contribution of Ontopsychology in understanding human knowledge: study of the concepts of important scholars from the Renaissance to Empiricism}

\begin{abstract}
Even considering the great names of Humanism, and its works, teachings, doubts and novelties, hereby now comprehending the years involving bold movements Renaissance and Empiricism, one shall not yet presume to have full comprehension of the evolution of human knowledge, and the human itself, without envolving the surging of Ontopsychology. This article will remember, within a historically rich time arch, new passages in the evolution of human knowledge and confront them with Antonio Meneghetti's thinking about each of them, therefore emphasizing the importance of understanding those arguments.
\end{abstract}

Keywods: Ontopsychology; Philosophy; Humanism; Renaissance; Empiricism.

\footnotetext{
${ }^{1}$ Para a leitura e compreensão do trabalho desta Pequena Tese do Módulo II, elaborada pelo autor, é importante destacar que a mesma é continuação do trabalho já iniciado e realizado na Pequena Tese do Módulo I do Curso de Bacharelado em Ontopsicologia, da Faculdade Antonio Meneghetti. A Pequena Tese do Módulo I encontra-se publicada na Edição Especial: Cadernos de Ontopsicologia - Iniciação Científica do Bacharelado em Ontopsicologia, na Saber Humano-Revista Científica da Faculdade Antonio Meneghetti, Ed. esp. de 2016, que pode ser acessada em: https://saberhumano.emnuvens.com.br/sh/article/view/100/124

2 Empresário, empreendedor, Pós-Graduação Lato Sensu MBA Gestão de Negócios e Intuição (AMF), estudante do Bacharelado em Ontopsicologia, I Turma, Faculdade Antonio Meneghetti - AMF. E-mail: adalberto@adsmicrologistica.com.br
} 


\section{Introdução}

"Entia non sunt multiplicanda praeter necessitatem"

"Não se multipliquem os entes se não for necessário"

Guilherme de Ockham

Tomemos como premissa a evolução da análise criteriosa das contribuições dos grandes viventes na Europa nos períodos conhecidos como Renascimento e Empirismo, e não as controvérsias elencadas em outros estudos, quando se começa a perceber uma simpatia crescente pelo confronto de opiniões em detrimento do acompanhamento dos registros históricos disponíveis. A discussão sobre a evolução do conhecimento parece enveredar, cada vez mais com a multiplicação das fontes de referência, muitas delas insustentáveis e irrelevantes, para uma discussão interminável e um confronto desnecessário entre opiniões. Cumpre este artigo o papel de elencar as principais ideias relacionadas ao conhecimento do Homem no período destacado, contrapô-las e explicá-las à luz do pensamento e com a contribuição de Antonio Meneghetti (1936-2013), e, assim, dar um passo seguinte na construção de uma linha do tempo estruturada e dedicada a ilustrar a evolução do conhecimento humano ao longo da História.

Dessa forma, como no artigo anterior, intitulado: "A insubstituível função da Ontopsicologia na compreensão do humano frente ao conhecimento proporcionado pelo Humanismo Clássico”, continua sendo objetivo geral deste breve estudo elencar as principais passagens da história da filosofia, seus protagonistas e suas evoluções, para deste modo sim, trazer cada uma para a discussão à ótica de análise da Ciência Ontopsicológica. Secundariamente, abrem-se duas oportunidades de: a) ainda assim estudar a contribuição do Humanismo Clássico para a formação do cientista Antonio Meneghetti e; b) transformar a dificuldade de elaboração da premissa precedente numa oportunidade única de estudo e evolução acadêmica - que também se configuram como nossos objetivos específicos.

Entretanto, depois de analisada a evolução do conhecimento filosófico da Antiguidade até a Escola Franciscana, agora serão apresentadas as ideias do Renascentismo Italiano de Leonardo da Vinci, Nicolau de Cusa, Marsílio Ficino, Giovanni Pico Della Mirandola, Jacopo Zabarella, Bernardino Telésio, Giordano Bruno e Tomás Campanella, não dispensando as contribuições de Michel de Montaigne, passando pela Revolução Científica de Francis Bacon, Galileu Galilei e Isaac Newton, o posicionamento de René Descartes e seus críticos sobre o método tais como Pierre Gassendi e Baruch Spinoza, conhecendo o Leviatã de Thomas 
Hobbes, as mônadas de Gottfried Leibniz e o empirismo de John Locke, e com George Berkeley, chegando ao Esse est percipi. Giambattista Vico e David Hume não serão visitados nesta oportunidade, porém, retomados num próximo artigo como contrapontos a serem destacados antes da confrontação da novidade de "A Crítica da Razão Pura" de Immanuel Kant (1724-1804) quando decide verificar em quais condições é possível um conhecimento objetivo, se é que este é possível ${ }^{3}$. Ainda há muito a ser estudado preliminarmente à colocação kantiana.

\section{Metodologia}

A elaboração deste artigo fundamentou-se na pesquisa bibliográfica de textos de referência (dicionários), de textos didáticos (história comentada da filosofia), de textos científicos (as obras de Antonio Meneghetti), de textos sobre a teoria do conhecimento (vide bibliografia, notadamente Margherita Carotenuto e a Antologia organizada por Marçal), e de notas de aula apresentadas durante o curso de graduação Bacharelado em Ontopsicologia da Faculdade Antonio Meneghetti, durante o Módulo II do Curso, na Primeira Turma, período de novembro de 2015 à julho de 2016.

O período estudado foi escolhido por inspiração da definição de Humanismo Histórico como "aquele encontrado em documentos e textos escritos, portanto da época e dos autores dos quais parte a racionalidade histórica da concepção de 'humanismo"' (MENEGHETTI, 2014a, p. 40). Outros consideram o Humanismo como o "movimento intelectual difundido na Europa durante a Renascença e inspirado na civilização greco-romana, que valorizava um saber crítico voltado para um maior conhecimento do homem e uma cultura capaz de desenvolver as potencialidades da condição humana"4, ou como "doutrina ou atitude que se situa expressamente numa perspectiva antropocêntrica, em domínios e níveis diversos, assumindo, com maior ou menor radicalismo, as consequências daí decorrentes" ${ }^{\prime 5}$. De qualquer modo, trata-se de um período muito importante em todos os aspectos, da história da evolução humana e do mundo por nós habitado.

\footnotetext{
${ }^{3}$ CAROTENUTO, Margherita. Histórico sobre as teorias do conhecimento. Recanto Maestro: Ontopsicológica Editora Universitária, 2009. p.104.

${ }^{4}$ Definição do site de busca Google. Disponível em: https://www.google.com.br/webhp?sourceid=chromeinstant\&ion=1\&espv=2\&ie=UTF-8\#q=humanismo $>$ acesso em: 14 de maio de 2016.

${ }^{5}$ FERREIRA, Aurélio Buarque de Holanda. Dicionário Aurélio da Língua Portuguesa. 5. ed. São Paulo: Editora Positivo, 2010. p. 1111.
} 


\section{Evolução Histórica do Pensamento Humanista: Renascimento, Racionalismo e}

\section{Empirismo}

Aponta Abbagnano (2012), em seu Dicionário de Filosofia, que as bases do Humanismo são:

1 Reconhecimento da totalidade do homem como ser formado de alma e corpo e destinado a viver no mundo e a dominá-lo. O curriculum de estudos medieval era elaborado para um anjo ou uma alma desencarnada. O Humanismo reivindica para o homem o valor do prazer (Raimondi, Filelfo, Valla); afirma a importância do estudo das leis, da medicina e da ética contra a metafísica (Salutati, Bruni, Valla); nega a superioridade da vida contemplativa sobre a vida ativa (Valla); exalta a dignidade e a liberdade do homem, reconhece seu lugar central na natureza e o seu destino de dominação desta (Manetti, Pico della Mirandola, Ficino).

2 Reconhecimento da historicidade do homem, dos vínculos do homem com o seu passado, que, por um lado, servem para uni-lo a esse passado e, por outro, para distingui-lo dele. Desse ponto de vista, é parte fundamental do Humanismo a exigência de descobrir os textos antigos e restituir-lhes a forma autêntica, estudando e colecionando os códices, mas também é a necessidade de encontrar neles o autêntico significado de poesia ou de verdade filosófica ou religiosa que contenham. A admiração pela Antiguidade e seu estudo nunca faltaram na Idade Média; o que caracteriza o Humanismo é a exigência de descobrir a verdadeira cara da Antiguidade, libertando-a dos sedimentos acumulados durante a Idade Média.

3 Reconhecimento do valor humano das letras clássicas. É por esse aspecto que o Humanismo tem esse nome. Já na época de Cícero e Varrão, a palavra humanitas significava a educação do homem como tal que os gregos chamavam de paidéia; eram chamadas de "boas artes" as disciplinas que formam o homem, por serem próprias do homem e o diferenciarem dos outros animais (AULO GÉLIO, Noct. Att., XIII, 17). As boas artes, que ainda hoje são denominadas disciplinas humanísticas, não tinham para o Humanismo valor de fim, mas de meio, para a "formação de uma consciência realmente humana, aberta em todas as direções, por meio de consciência histórico-crítica da tradição cultural” (GARIN, L'educazione umanistica in Italia, p. 7).

4 Reconhecimento da naturalidade do homem, do fato de o homem ser um ser natural, para o qual o reconhecimento da natureza não é uma distração imperdoável ou um pecado, mas um elemento indispensável de vida e de sucesso. O reflorescimento do aristotelismo, da magia e das especulações naturalistas (graças a Telésio, Giordano Bruno e Campanella) constituem o prelúdio da ciência moderna (ABBAGNANO, 2012, p. 602-603).

Entretanto, tal descrição não demonstra a origem, isto é, a base de tais valores. Resgata-nos, então, Meneghetti (2014a), quando define os valores do Humanismo históricocivil alicerçados não apenas no que defendiam diferentes autores, mas no cotidiano da sociedade da época:

O Humanismo histórico-civil florentino-italiano, que permanece o período mais alto que a história tenha vivido para a cultura humanista, encorajava uma atividade social em liberdade e dignidade do homem, ou seja, promovia o desenvolvimento de 
quatro valores principais: a vida ativa, a socialidade, a liberdade e a dignidade do homem.

1) Vida ativa: é válido quem opera ativamente, de fato a verdade se faz agindo agora, não é algo que se crê, espera ou sonha. Ação em conformidade com aquela intencionalidade de natureza intrínseca ao projeto em situação.

2) Socialidade: o indivíduo é extraordinário, mas é um ser social, por isso, na sua atividade e existência deve sempre fazer evolução em conjunto com os outros, também estes empenhados em caminhar para construir dignidade. O conceito profundo de "socialidade" não implica assistencialismo: não se fala de caridade, mas sim de responsabilidade. Os assim ditos "pobres" são ajudados a tornar-se, não devem ser substituídos naquilo que podem fazer: é inútil saciá-los, é preciso oferecer a eles a cultura que faz superior o ser humano, tornando-o expoente de um bem-estar integral. Tudo isso não é um excesso, mas uma necessidade daquela virtualidade que o homem é ("mesmo na desgraça há um fator de responsabilidade ou inconsciente. Os líderes da imagem, da cultura, da democracia cívica e humanista, se querem amar e cumprir o próprio mandato interior, ao invés de atacar, criticar os vencedores e fazer cruzadas de assistencialismo biológico e formalizar cumplicidade caridosa com o inferior, devem dar consciência crítica à oportunidade de saber ser dignidade autônoma e colaborador social: caso contrário, os standard marginalizados são o canovaccio $^{6}$ do parasitismo social e a degradação da própria pessoa e de outros" ${ }^{7}$. O valor da "socialidade" contém os conceitos profundos de "política", "civitas", portanto, o indivíduo não só homem (a humanidade em sentido geral) e pessoa (ser individuado), mas também cidadão. Na Itália o conceito de "cidadania" era claro e distinto já em 1300/1400: o que é o Estado, quais são os direitos e deveres, qual é o modo - segundo possibilidades práticas - para tornar melhor a sociedade, qual é o valor da família, da pátria, etc. (No Humanismo é fortíssimo o conceito de "pátria", enquanto esta é a defesa natural da psicologia territorial da qual cada indivíduo livre tem necessidade. $\mathrm{O}$ ser humano tem necessidade de estradas, casas, etc., isto é, de um espaço ordenado que seja funcional à socialidade, seja à realização dos escopos do homem como indivíduo. Cada um de nós se define "Eu" porque existe sempre o "Tu", o outro. Ao defender a pátria se defende o próprio segundo espaço, depois o próprio corpo, e esse é um direito que pertence a cada homem. Sucessivamente, deflagram-se as diversas dialéticas econômico-políticas.

3) Liberdade: esse valor era fundamental, de fato, o tirano era considerado o primeiro fora da lei e o pior inimigo da comunidade, pois constituía uma poderosa ruína daquela socialidade e liberdade que a natureza oferece a cada homem. Portanto, para os humanistas é um direito da comunidade matar qualquer um que, com o poder do qual dispõe, age contra os interesses da coletividade.

4) Dignidade do homem: esse valor é o fundamento a todos os outros. Os autores do Humanismo histórico-civil italiano falam explicitamente da dignidade, isto é, o dever de respeito, de sacralidade, transcendência, superioridade que todo homem tem defronte a um outro homem ou a uma outra autoridade qualquer. O homem resulta por aquilo que faz, não por aquilo que pensa. Ele cria continuamente novas realidades (também a si mesmo), portanto é um 'segundo criador' (MENEGHETTI, 2014a, p. 56-59).

Assim, retomamos a partir de tal valor fundamental, a dignidade do homem. Temos, então, o Renascimento, "que pode ser considerado o fruto do Humanismo"».

A Itália do século XV inicia o rompimento com as tradições medievais, tornando-se um terreno fértil para o desenvolvimento da arte, da filosofia, da medicina, da política, da

\footnotetext{
${ }^{6}$ Canovaccio pode ser compreendido como um roteiro de uma comédia teatral sobre o qual o elenco improvisa, linha mestra da trama, script (MENEGHETTI, 2014a, p. 57).

${ }^{7}$ MENEGHETI, Antonio. O líder intelectual o que pode e deve fazer. In: Revista Nova Ontopsicologia, n.1/2001. Recanto Maestro: Ontopsicologica Editrice. p. 4-12.

${ }^{8}$ MENEGHETTI, Antonio. Do Humanismo Histórico ao Humanismo Perene. Recanto Maestro:

Ontopsicológica Editora Universitária, 2014a. p.68.
} 
economia, da música e da ciência de forma nunca antes experimentada pela humanidade. A atividade comercial se expande tremendamente - ao que nos dias de hoje encontraria paralelo na chamada "globalização" -, as fronteiras são alargadas pelo descobrimento do Novo Continente - hoje conhecido como Continente Americano - e a inteligência, digamos, "empresarial" descortina novos horizontes para a cultura, o bem-estar e o desenvolvimento humano com o surgimento do sistema bancário nos moldes modernos. Toda a Europa a segue.

Invenções como a prensa de Johann Gutemberg (1455), o moinho de vento de Agostino Ramelli (1589), a luneta de Galileu Galilei (1609), e o microscópio de Antoin van Leeuwenhoek (1683), alavancam o desenvolvimento da sociedade por mais de duzentos anos. Avanços na compreensão do funcionamento do corpo humano - noções da anatomia humana com Andreas Vesalius (1543); circulação pulmonar, Michael Serventus (1553); funcionamento do coração, William Harvey (1628); descoberta das células, Robert Hooke (1665) - contribuem enormemente para a superação dos pressupostos "divinos" que até então explicavam o homem e sua biologia.

No campo científico, dá-se um salto significativo com a representação tridimensional do globo terrestre de Martim Behaim (1492), os estudos sobre o heliocentrismo de Nicolau Copérnico (1543), o estudo da mineralogia por Georgius Agricola (1556), a descoberta da órbita dos planetas por Johannes Kepler (1610), a Geometria Analítica de René Descartes (1637), o enunciado da Lei da Gravitação Universal de Isaac Newton (1687), a publicação da Teoria das Probabilidades por Blaise Pascal e Pierre Fermat (1654), e a descoberta da órbita dos cometas por Edmond Halley (1705), dentre outros avanços. Nas artes, tanto as telas passam a ser utilizadas em substituição à madeira para a representação por meio da pintura, quanto se inova na utilização da perspectiva, com representações tridimensionais em superfícies planas 9 .

Em suma, o Renascimento muda o mundo, que nunca mais será o mesmo.

Meneghetti (2014a) registra a transferência de grandes mentes para a Itália, "levando consigo os textos antigos das humanae litterae, principalmente aqueles de Platão, Aristóteles, mas também de Cícero e outros". O Renascimento é uma "época que viu surgir nova cultura, oposta à medieval"10. O mundo migra da "época da escuridão e das trevas" para a "época da luz”. Temos aqui: reforma, renovação, renascimento.

\footnotetext{
${ }^{9}$ Relembre 20 invenções e avanços tecnológicos da Renascença. Disponível em: $<$ http://super.abril.com.br/relembre-20-invencoes-e-avancos-tecnologicos-da-renascenca> acesso em: 13 de maio de 2016.

${ }^{10}$ REALE, Giovanni; ANTISERI, Dario. História da Filosofia - Patrística e Escolástica. Volume 2. São Paulo: Paulus, 2015. p. 25.
} 
Assim, o Renascimento representou grande fenômeno espiritual de "regeneração" e "reforma", no qual o retorno aos antigos significou revivescência das origens, "retorno aos princípios", ou seja, retorno ao autêntico. É também nesse espírito que deve ser entendida a imitação dos antigos, que se revelou o estímulo mais eficaz para que os homens encontrassem, recriassem e regenerassem a si próprios (REALE e ANTISERI, 2015, p. 25).

Nesta seara, afirma Meneghetti (2010):

Tudo isso é favorecido pela Igreja Católica, porque se tratava de redescobrir o período helênico, quando escreviam os Evangelistas, por isso era importante entender o grego antigo, para compreender qual havia sido a predisposição ao evento do Messias. Enquanto se favorece tudo a essa cultura, os intelectuais das Senhorias começam a compreender uma nova ideologia, não mais exclusivamente aquela da Igreja Católica como mediadora de Deus na Terra, mas a cultura do homem laico da pólis, isto da civitas, do homem sem mitos. Ao mesmo tempo, as Senhorias conquistam maior autonomia do poder do papado. A Itália vive uma espécie de "ressurgimento" da cultura greco-romana antiga, porque tem acesso a livros que não tinham sido filtrados ou feitos desaparecer: são os textos originais dos autores pagãos. Isso cria um enriquecimento, o acréscimo de uma outra história, na qual a arte é lida e interpretada em um novo modo, por isso se entra em uma outra visão, em que, de qualquer modo, o soberano epicentro é o homem. Que seja em forma pagã, seja cristã, seja árabe, de qualquer modo o homem é o portador. Nesses anos, não se fala mais de Cristo e dos santos, mas da primeira racionalidade do homem" (MENEGHETTI, 2010, p. 69-70).

Demonstrado o pano de fundo deste novo momento histórico, entram em cena os grandes pensadores, trazendo, cada um, sua visão sobre a evolução do conhecimento humano.

Leonardo da Vinci (1452-1519), afirma que "toda a cognição principia com os sentidos" e "o saber não pode limitar-se a uma dimensão teórica, mas deve traduzir-se em capacidade operativa, em tecnologia" ${ }^{\text {11 }}$. Leonardo da Vinci marcou a história da Humanidade com suas invenções, isto é, exatamente não limitando o saber a uma dimensão teórica, mas traduzindo-o em capacidade operativa. O rolamento, o equipamento de mergulho, o ornitóptero, o helicóptero, o carro auto-propelido, o paraquedas, o tanque blindado e o anemômetro, todos desenvolvidos por ele à época, transformaram ideias em avanços tecnológicos para o benefício de toda a humanidade.

Contemporaneamente, Nicolau de Cusa (1401-1464) "distingue entre a ratio discursiva e o intellectus intuitivo: apenas este último é capaz de elevar-se acima da razão e do seu princípio de não-contradição até entrever a paradoxal coincidentia oppositorum do infinito" . Dessa forma, Carotenuto (2009) infere que:

\footnotetext{
${ }^{11}$ CAROTENUTO, Margherita. Histórico sobre as teorias do conhecimento. Recanto Maestro: Ontopsicológica Editora Universitária, 2009. p. 59.
} 
Nenhum conhecimento pode ser definitivo, porque ele pode aproximar-se cada vez mais do seu objeto, mas é destinado a permanecer sempre uma diferença entre os dois, jamais inteiramente preenchível (...) entre conhecimento e verdade há uma insuperável diferença, que torna o conhecer conjectural e tal conjecturalidade não se refere apenas à infinidade divina, mas também ao universo que, sendo infinito como o seu criador, não consente à razão atingir seu completo conhecimento (CAROTENUTO, 2009, p. 59).

E, por que o universo não consente à razão atingir seu completo conhecimento? A visão do divino, na verdade, prevalece como algo inalcançável ou estamos a romper com as "verdades" pregadas pela Igreja nos períodos precedentes? Nesse sentido, Meneghetti (2010) explica:

Enquanto na cultura cristã existe o conceito de "pecado original", segundo os humanistas o homem é bom por natureza: pode ser arruinado em seguida, mas no princípio da sua natividade é intacto. Além disso, é uma entidade espiritual, portanto é transcendente nos seus modos de fazer e resulta superior em relação aos outros seres viventes. (...) O Humanismo não aceita a imortalidade do homem: não é que a exclua, simplesmente não se vê, não o é algo de racional. O Humanismo está na práxis existencial: fala-se do homem espiritual, transcendente, coligado ao sentido apriórico das coisas do mundo-da-vida, mas não por isso o homem é considerado imortal. (...) Portanto, a ideia de uma alma imortal permanece fora da lógica do Humanismo e isso implica a responsabilidade de fazer aqui, não de esperar o além: agora urge ação e inteligência (da qual o valor da "vida ativa") (MENEGHETTI, 2010, p. 73-74).

Marsílio Ficino (1433-1499), quando publica Theologia Platonica, diz que "o inteiro universo é um organismo unitário dirigido pelo princípio do amor que mantém juntas todas as suas partes. Todo o finito tende a Deus e tal processo de tensão concentra-se na alma. (...) a alma é a copula mundi, recolhe a totalidade e unifica-a em si"12.

Trata-se de um acréscimo à "tarefa fundamental que o homem deve cumprir, segundo os humanistas, que é a autorrealização, na qual é fundamental a felicidade individual e a possibilidade de gozar das próprias capacidades" "13. Na visão otimista do Humanismo "o homem pode vencer, pode resolver, é capaz, pode participar da criação"14. Ademais, Ficino (1433-1499) "reinvindica que a tolerância é o conceito-chave para unir e manter a unidade de ação entre culturas diversas e que cada homem é um microcosmo, isto é, tem em si a totalidade do macrocosmo. Por isso, a consequência é que o homem que conhece e compreende a si mesmo, conhece e sabe também o inteiro" ${ }^{\text {} 15}$.

\footnotetext{
12 Ibidem, p. 59-60.

13 MENEGHETTI, Antonio. Do Humanismo Histórico ao Humanismo Perene. Recanto Maestro: Ontopsicológica Editora Universitária, 2014a. p. 75.

${ }^{14}$ Ibidem, p.75.

${ }^{15}$ Ibidem, p.75.
} 
Célebre pela publicação do Discurso sobre a dignidade do homem ${ }^{16}$, Giovanni Pico Della Mirandola (1463-1494) afirma que "o homem foi criado à imagem e semelhança de Deus, é um microcosmo que recolhe realmente e idealmente em si os elementos de toda as coisas. Portanto, o homem não é determinado e forçado, mas chamado a escolher e isto constitui a sua dignidade. Tal escolha não é arbitrária, porque se desenvolve no interior de um leque definido de possibilidades. A sua liberdade é um dom e um dever que o endereça a elevar-se ao divino para buscar a união mística com ele.

Tal ascensão a Deus se realiza através de três graus: purificação, iluminação e unificação"17. Meneghetti (2014a) complementa dizendo que o autor "considera o homem uma obra de natureza indefinida, a qual Deus não atribui um lugar bem definido, por isso, o ser humano é faber fortunae suae ${ }^{18}$ no sentido mais alto, isto é, é continuamente o resultado do que ele mesmo faz para si mesmo", e prossegue com "o que emerge, em modo ampliado, é que o homem é um ser perfectível: não somente é criado de um certo modo, mas em seguida, se torna a estrada justa, pode crescer e aperfeiçoar-se. É aquilo que em Ontopsicologia se chama "autóctise histórica" funcionalidade maior e mais precisa. Naquilo que somos como alma somos perfectíveis, se realizamos ações que produzem autogênese da nossa identidade, que depois se traduz em ação, socialidade, liberdade, etc., também para os outros"20.

Carotenuto (2009, p. 62) afirma que "a partir da metade do século XVI, a questão da alma passa ao segundo plano e os aristotélicos de Padova concentram-se no problema do método científico". Em particular, Jacopo Zabarella (1533-1589) antecipa alguns aspectos do método hipotético-dedutivo galileano e distingue entre método da composição ou sintético, típico da matemática e consistente no deduzir o efeito a partir da causa, e método da resolução ou analítico, típico das ciências físicas e consistente em ascender à causa a partir do efeito observado pela experiência.

Michel de Montaigne (1533-1592) “considera que a única via de acesso à verdade seja oferecida pela 'graça', não pela razão", além disso, considerada também que:

\footnotetext{
${ }^{16}$ Oratio de hominis dignitate, em latim (tradução livre).

${ }^{17}$ CAROTENUTO, Margherita. Histórico sobre as teorias do conhecimento. Recanto Maestro: Ontopsicológica Editora Universitária, 2009. p. 61.

${ }^{18}$ Nota do autor: faber fortunae suae, também expressa em sua versão alternativa faber ipsius fortunae, significa que o homem "é artífice da própria sorte".

${ }^{19}$ Conforme Dicionário de Ontopsicologia, "autoconstituição, processo histórico de escolhas existenciais que fazem a resultante da evolução e da situação pessoal" (MENEGHETTI, Antonio. Dicionário de Ontopsicologia. 2. ed. Recanto Maestro: Ontopsicológica Editora Universitária, 2008).

20 MENEGHETTI, Antonio. Do Humanismo Histórico ao Humanismo Perene. Recanto Maestro: Ontopsicológica Editora Universitária, 2014a. p. 77.
} 
Nem os sentidos, nem a razão são capazes de dar um critério seguro de conhecimento, os sonhos e as ilusões testemunham a incerteza das nossas evidências sensíveis (...) [talvez] a verdade definitiva seja uma meta inalcançável e (seja) preciso, antes, apontar para uma certeza subjetiva, para uma fé que não seja dogmática, mas coincida com a própria atitude de pesquisa e de dúvida ${ }^{21}$.

Bernardino Telésio (1509-1588) afirma que:

Com base na sensação, desenvolvem-se a memória, a imaginação e, enfim, a inteligência, através da qual se chega (por semelhança e em virtude da memória, que conserva as experiências precedentes) a inferir o que não é atualmente percebido do que é agora presente ao sentido. Logo, a inteligência não é distinta do sentido, mas, pelo contrário, deve ser reconduzida a ele: a sua atividade cognoscitiva é uma forma de sensação enfraquecida, mas imperfeita porque é indireta ${ }^{22}$.

E que, portanto, "a consequência (é) que os próprios animais raciocinam e que a diferença entre o pensamento dos homens e aquele dos animais é apenas quantitativa e não qualitativa. Porém, o homem tem a mais uma substância divina incutida diretamente pelo próprio Criador, a mens superaddita" 23.

Giordano Bruno (1548-1600) "distingue duas atitudes diante da realidade: aquela do sapiente, indiferente aos extremos e às contrariedades da existência; e aquela do furioso (louco) o qual, por um defeito de conhecimento que lhe impede de colher a vanidade de toda a paixão, apaixona-se pelos extremos, desequilibra-se", enquanto "no heroico furor se fundam intelecto e vontade, paixão e razão, é uma repentina ascensão da alma que leva o homem a fixar o olhar sobre a verdade: a unidade infinita do todo" ${ }^{, 24}$.

Tomás Campanella (1568-1629) define que "a forma mais universal e exaustiva de conhecimento é a metafísica, cujo primeiro dever é de demonstrar a possibilidade de chegar a um conhecimento verdadeiro e certo", pois afirma Carotenuto (2009) acerca de Campanella:

O conhecimento que a alma tem de si mesma não é algo 'além' do seu ser, algo que se adiciona, mas é a própria alma, enquanto presente a si. O ser da alma é, portanto, (também) conhecimento de si, um conhecimento inato, que (ele próprio, Campanella) define sabor de si ou senso de si. A alma conhece, antes de tudo, a si mesma, depois conhece também os outros entes, mas em tal caso se trata de um conhecimento indireto (addito, ou seja, adicionado), uma vez que não conhece os entes, mas a si mesmo pelo modo como é modificada por estes. Trata-se sempre de

\footnotetext{
${ }^{21}$ CAROTENUTO, Margherita. Histórico sobre as teorias do conhecimento. Recanto Maestro: Ontopsicológica Editora Universitária, 2009. p. 64.

${ }^{22}$ Ibidem, p. 65-66.

${ }^{23}$ Ibidem, p. 65-66.

${ }^{24}$ CAROTENUTO, Margherita. Histórico sobre as teorias do conhecimento. Recanto Maestro: Ontopsicológica Editora Universitária, 2009. p. 66.
} 
um enriquecimento do sujeito, mas agindo sobre o conhecimento que a alma tem de si, perturba-se e obscura-se a sua pureza. Isso determina o fato que a alma, enquanto adquire conhecimento das coisas e, à medida que o faz, torna-se menos autoconsciente ${ }^{25}$.

Nesse momento, Carotenuto (2009) discorre sobre a chamada Revolução Científica, destacando as contribuições diretas de Nicolau Copérnico (1473-1543) e Isaac Newton (16431727), com suas respectivas publicações De revolutionibus orbium coelestium ("Das revoluções das esferas celestes", 1530), e Philosophiae naturalis principia mathematica ("Os princípios matemáticos da filosofia natural”, 1687). Apresenta a autora, ato contínuo, os principais fatores dessa "revolução":

- Superação da distinção entre astronomia física celeste e física terrestre, a descoberta de que não são diversas por natureza, mas que estão sob os mesmos princípios;

- Afirma-se a concepção mecanicista, a máquina substitui o vivente como modelo da realidade natural e humana. Substitui-se o finalismo das metafísicas clássicas pelo determinismo;

- Crítica do princípio de autoridade: a experiência e a razão são consideradas maiores garantias de verdade em relação às antigas doutrinas;

- Muda o conceito de ciência e verdade científica. Intensifica-se a cooperação entre engenheiros, técnicos e cientistas; e os instrumentos produzidos pela técnica (ex: luneta) têm papel determinante na pesquisa científica. Substitui-se o ideal contemplativo da ciência clássica e medieval por uma mais forte consciência da utilidade prática do saber científico. Afirma-se a concepção da natureza aberta, não definitiva, progressiva e pública do saber científico;

- Nasce a linguagem científica moderna, inspirada em exigências de rigor e clareza "geométrica", não sofrendo do caráter vago e alusivo da terminologia filosófica e científica tradicional;

- Torna-se central o problema do método do conhecer, já presente em Platão (discussões sobre o método da diairésis) e Aristóteles (distinção entre as ciências em base ao método das mesmas) e na escolástica medieval, tanto é que o substantivo methodus - equivalente ao grego méthodos, percurso, via através da qual - já indicava a melhor via para atingir o conhecimento de algo;

- A insatisfação com o aristotelismo dá amplo espaço ao ceticismo, mas é justamente a exigência de salvaguardar a ciência das objeções dos céticos que impulsiona a pesquisa de novos e mais seguros critérios e regras do conhecer. Aos argumentos dos céticos, filósofos e cientistas como Galilei, Bacon e Descartes opõem a convicção de que o erro não é conatural ao homem, uma consequência ineliminável da razão e dos sentidos, mas derivante de um uso incorreto da razão (CAROTENUTO, 2009, p. 68-69).

Interessa-nos trazer, também, a análise de Reale e Antiseri (2015) acerca do mesmo período, em síntese:

- Trata-se de poderoso movimento de ideias que adquire no século XVII as suas características determinantes na obra de Galileu, que encontra os seus filósofos em aspectos diferentes - nas ideias de Bacon e Descartes e que depois encontraria

\footnotetext{
${ }^{25}$ Ibidem, p. 67.
} 
sua expressão agora clássica na imagem newtoniana do universo concebido como máquina, ou seja, como relógio;

- O elemento detonador desse processo de ideias foi certamente a "revolução astronômica", que teve seus representantes mais prestigiosos em Copérnico, Tycho Brahe, Kepler e Galileu e que confluiria para a "física clássica" de Newton. Nesse período, por tanto, muda a imagem do mundo;

- Vinculada a essa transformação, dá-se também a mudança - que também foi lenta e tortuosa, mas decisiva - das ideias a respeito do homem, acerca da ciência, concernente ao homem de ciência, no tocante ao trabalho científico e as instituições científicas, relativamente às relações entre ciência e sociedade, entre ciência $e$ filosofia e entre saber científico e fé religiosa;

- Mudando a imagem do mundo, muda a imagem do homem. Mas também, progressivamente, muda a imagem da ciência. A revolução científica não consiste somente em adquirir teorias novas e diferentes das anteriores a respeito do universo astronômico, acerca da dinâmica, a respeito do corpo humano ou, talvez, sobre a composição da Terra. Ao mesmo tempo, a revolução científica é revolução da ideia de saber e de ciência;

- A ciência - e esse é o resultado da revolução científica, resultado que Galileu explicitaria com clareza absoluta - não é mais a intuição privilegiada do mago ou astrólogo iluminado, individualmente, nem o comentário a um filósofo (Aristóteles) que disse "a verdade e toda a verdade, isto é, não é mais discurso sobre o 'mundo de papel', mas sim investigação e discurso sobre o mundo da natureza;

- Com a revolução científica, "abriu-se o caminho para as categorias, os métodos, as instituições, os modos de pensar e os valores relacionados com o fenômeno que, depois da revolução científica, costumamos chamar de ciência moderna" (Paulo Rossi). E o traço mais característico desse fenômeno que é a ciência moderna resume-se precisamente no método, que, por um lado, exige imaginação e criatividade de hipóteses e, por outro lado, o controle público dessas imaginações;

- E é com base no método experimental que se funda a autonomia da ciência, que encontra as suas verdades independentemente da filosofia e da fé (REALE e ANTISERI, 2015, p.185-187).

Conceitualmente, o método é compreendido por um conjunto de critérios, regras, e lógicas que se aplicam a um experimento para, sempre considerando o "uso correto das faculdades cognoscitivas". Todavia, novamente se apresenta a questão basilar em torno desse "uso correto". Ainda que com o Renascimento:

Nasce o homem moderno, que não é fácil de ser compreendido, enquanto é complexo. Através da sua globalização, o homem percebeu que as suas fés, convicções, políticas etc., são todas relativas. Existem tantos povos, diversas culturas, por isso o homem se ampliou como em um oceano: aquilo que antes era seguro e tranquilo na aldeia, hoje se tornou oceano, curiosidade, responsabilidade de novas descobertas, de novo caminho ${ }^{26}$.

Tem-se aqui o homem exato capaz de, sem contradições, fazer o "uso correto das faculdades cognoscitivas"?

Quaisquer experimentos (científicos) devem ser capazes de evidenciar a origem e o desenvolvimento dos fenômenos estudados. Existe, assim, um raciocínio inicial hipotético,

26 MENEGHETTI, Antonio. Do Humanismo Histórico ao Humanismo Perene. Recanto Maestro: Ontopsicológica Editora Universitária, 2014a. p. 78. 
que evolui para a demonstração factual e incontroversa da primeira hipótese. Portanto, defende Carotenuto (2009) que se:

Para a ciência aristotélica a experiência não basta para conhecer a verdade, que de todo modo existe; para a ciência moderna, ao contrário, só através da experiência pode-se atingir um conhecimento com um elevado grau de verossimilhança, mas a verdade é uma tensão, uma pesquisa, não um fato certo (CAROTENUTO, 2009, p. 71).

Francis Bacon (1561-1626) propõe, então, uma reforma do método, baseando-se em dois conceitos: pars destruens (demolição dos erros) e pars construens (pesquisa da forma). Lista, assim, as críticas dos erros ${ }^{27}$ primeiramente, e depois: a) classifica e registra os dados observados; b) formula uma primeira hipótese sobre a "forma" e, por fim c) convalida (ou rejeita) experimentalmente a hipótese formulada. Se Bacon se apoia nas tais tabelas classificatórias, Galileu Galilei (1546-1642) defende a matematização do experimento, isto é: a) selecionando e observando na experimentação somente alguns aspectos fundamentais mensuráveis e, desta forma, quantificáveis, ou b) considerando o fenômeno observado segundo suas propriedades geométricas. Resumidamente, o método galileano prevê três momentos:

\begin{abstract}
- Momento de observação: observação sistemática, matematização dos dados observados, quantificação e medida, e seleção dos aspectos geométricos/mecânicos;

- Momento técnico-explicativo: formulação por hipóteses de uma teoria ou lei matemática (a lei "explica" os dados observados indicando como se desenvolve constantemente o fenômeno estudado);

- Convalidação e verificação experimental: controle/verificação empírica das previsões feitas com base à teoria ou lei formulada (por ela deduzidas), construção de experimentos, ou seja, de ocasiões de interrogação ativa da natureza, por meio de instrumentos, e experimentos mentais, ou seja, imaginários (CAROTENUTO, 2009, p.73).
\end{abstract}

René Descartes (1596-1650), publica O discurso sobre o método em 1637. Na obra, define as regras do método tal como:

Regra I - Evidência: Jamais acolher por verdadeiro algo que nunca tenha sido objeto de uma ideia clara e distinta, ou seja, evitar acuradamente a precipitação e a prevenção e não compreender nos próprios juízos nada além do que se apresenta assim clara e distintamente à inteligência, a ponto de excluir toda possibilidade de dúvida.

Regra II - Análise: Dividir cada problema a estudar em tantas partes menores quanto seja possível e necessário para melhor resolvê-lo.

Regra III - Síntese: Concluir com ordem os próprios pensamentos, começando dos objetos mais simples e fáceis de conhecer, para subir pouco a pouco, como que por

\footnotetext{
27 “Idola tribos (erros que se radicam na natureza humana), idola specus (erros que derivam dos hábitos individuais, da educação), idola fori (erros que se referem à linguagem) e idola theatri (erros nascidos com as filosofias" (CAROTENUTO, 2009, p. 71).
} 
degraus, até o conhecimento dos mais complexos, e supondo uma ordem também entre aqueles dos quais uns não precedem naturalmente os outros.

Regra IV - Enumeração: Fazer, onde for possível, enumerações tão completas e revisões tão gerais a ponto de estar seguro de não ter omitido nada. (CAROTENUTO, 2009, p. 75).

Considerado o "fundador da filosofia moderna", René Descartes, apesar da novidade apresentada, traz em suas ideias uma dúvida metódica:

Suponho que todas as coisas que vejo são falsas. Fixo-me bem na mente que nada existiu de tudo o que minha memória, cheia de mentiras, me representa; penso não ter sentido algum; creio que o corpo, a figura, a extensão, o movimento e o lugar não são nada mais do que invenções do meu espírito. Então, o que poderá ser reputado verdadeiro? Talvez nada mais além do fato de que não há nada de certo no mundo! $!^{28}$

Longe de ser prejudicial, a dúvida de Descartes contribui para, digamos, uma reavaliação da consciência tradicional. Sem a dúvida, não existe a liberdade de um novo pensamento. Em sentido oposto, porém complementar, lança o autor uma certeza fundamental: cogito ergo sum ("penso, logo sou”). Entretanto, Pierre Gassendi (1592-1655) o contradiz, sublinhando "o caráter irremediavelmente subjetivo do critério de verdade cartesiano, considerando-o inadequado para decidir sobre a verdade objetiva do nosso conhecer, não apenas em relação às sensações, mas também aos objetos da intuição intelectual", estendendo "sua crítica ao pretenso valor da verdade do conhecimento racional" insistindo "no caráter apenas probabilístico e hipotético do conhecimento" (CAROTENUTO, 2009, p. 77).

A partir do raciocínio cartesiano, descortina-se um novo capítulo da evolução do pensamento Humanista. Nasce e consolida-se a Ciência Moderna. Vários autores se destacam, tais como os que serão a partir daqui apresentados neste texto.

Thomas Hobbes (1588-1679), autor de O Leviatã (1651), contribui com a distinção entre dois tipos de conhecimento, ou seja, 1) o conhecimento comum, dito também originário e factual, funda-se na experiência sensível, que produz imagens sensíveis - as imagens sensíveis, através da imaginação, ou memória, conservam-se como ideias, que são imagens sensiveis desfocadas; tanto as imagens sensíveis quanto as ideias tem conteúdo singular, e 2) o conhecimento científico ou filosófico (filosofia e ciência para Hobbes são a mesma coisa), baseia-se no conhecimento comum, do qual é uma complexa reelaboração, por isso é dito também conhecimento derivado - as imagens sensíveis e as ideias conservadas na memória

\footnotetext{
${ }^{28}$ REALE, Giovanni; ANTISERI, Dario. História da Filosofia - Patrística e Escolástica. Volume 2. São Paulo: Paulus, 2015. p. 363.
} 
são coligadas entre elas pela memória associativa, dando lugar a hábitos e previsões; diferentemente do conhecimento comum, a ciência não se limita a constatar como a realidade é factualmente, mas propõe-se a explicar suas razões e indicar suas causas ${ }^{29}$. A despeito da novidade de suas ideias, Hobbes corrobora com a visão dos autores a ele precedentes ao responsabilizar a "falta de método" pelos erros cometidos pelos filósofos, defendendo que a "filosofia deve apropriar-se do modelo da geometria e proceder à rigorosa e unívoca determinação do significado"30.

A obra De intellectus emendatione, de Baruch Spinoza (1632-1687), apresenta a ideia do sumo bem, isto é, a verdade que dá significado à vida, em contraponto à verdade científica, e distingue quatro graus de conhecimento:

- Aquele por ouvir dizer, que nos leva a seguir as opiniões dos outros;

- Aquele por experiência vaga, na qual nos fundamos sobre nossa experiência adquirida casualmente;

- A razão demonstrativa, mediante a qual vamos dos defeitos à causa; e

- A intuição, com a qual conhecemos os efeitos através das causas e o ente incausado (Deus) diretamente na sua essência (CAROTENUTO, 2009, p. 80).

Aqui, diferentemente de Descartes, não há dúvida metódica. Da constatação intuitiva, pode-se partir para a pesquisa da realidade. Tanto Spinoza defende um perfeito paralelismo entre ordo idearum (ordem do conhecimento) e ordo rerum (ordem da inteira natureza), que assume "como critério de verdade a correspondência entre a ideia verdadeira e seu ideado", retomando "a doutrina escolástica adaequatio mentis et rei" (CAROTENUTO, 2009, p. 80$81)^{31}$.

Isto posto, o confronto entre Descartes e Spinoza apresenta um ponto em comum - a moral provisória - e quatro divergências, respectivamente a cada um dos autores: 1) método científico versus emendação do intelecto; 2) parte da dúvida versus parte da ideia verdadeira; 3) verdade $=$ certeza versus verdade $=$ objetividade, e 4) nítido dualismo sensível-inteligível versus passagem gradual do sensível ao inteligível (ibid., p. 78).

Já Gottfried Leibniz (1646-1716), em seu pensamento:

Concebe a substância como um ser capaz de ação, logo critica a hipótese corpuscular ou atomista, mas também a ideia cartesiana de extensão. A existência, para Leibniz, é feita de mônadas, substâncias simples e indivisíveis, um centro inextenso de força e atividade. O mundo dos corpos não tem, portanto, uma realidade absoluta, é apenas um fenômeno bem fundado (...). Cada mônada é um

\footnotetext{
${ }^{29}$ CAROTENUTO, Margherita. Histórico sobre as teorias do conhecimento. Recanto Maestro: Ontopsicológica Editora Universitária, 2009. p. 78.

${ }^{30}$ Ibidem, p.79.

${ }^{31}$ Nota do autor: Adaequatio mentis et rei: “(A verdade) é a adequação da inteligência e da coisa”, isto é, ao verificar se uma ideia é verdadeira, é preciso verificar sua correspondência ao objeto real.
} 
pequeno mundo concebido em um ponto. Retomando a doutrina aristotélica da analogia, Leibniz explica que isso é possível, caso se entenda a atividade interna das mônadas como uma atividade de simbolização do inteiro universo, ou seja, como expressão. Assim, a relação entre a mônada singular e o inteiro universo deve ser concebida como uma relação de recíproca expressão, ou seja, de analogia e proporção, entre as partes e o todo ${ }^{32}$.

Para Leibniz "apenas a experiência não é suficiente para explicar o processo do conhecimento, no sentido que a pretensa universalidade e necessidade das leis científicas não pode ter um fundamento puramente empírico" 33 , acrescentando ao dito nihil est in intellectu quod prius non fuerit in sensu (nada está na mente que não tenha estado previamente nos sentidos), nise ipse intellectu (a não ser o próprio intelecto). E ainda: “A alma dispõe de um patrimônio inato, que se atua na concreta experiência sensível e recebe do intelecto a sua perfeição racional" (LEIBNIZ, citado por CAROTENUTO, 2009, p. 85).

Cabe aqui uma importante passagem da construção da tese ontopsicológica, conforme o Manual de Ontopsicologia, quando MENEGHETTI (2010) salienta que:

O homem se qualifica quando o seu pensamento constrói ação racional e, pelos efeitos, pode-se discriminar a informação ôntica da informação memética, do parasitismo psicobiológico que depois determina o homem alienado até o estresse, provocando a insegurança da própria consciência, da própria orientação e, definitivamente, de si mesmo (MENEGHETTI, 2010, p. 127).

Retomando, afrontamos o empirismo e seu expoente principal, John Locke (16321704). Face à questão da extensão do conhecimento humano, Locke afirma que o conhecimento deriva dos sentidos e que o que resulta fora da nossa experiência não é cognoscível. A seguir, propõe "um método concreto e analítico, dirigido a dar uma explicação dos modos com os quais o nosso intelecto adquire as noções que tem das coisas e a estabelecer seja os degraus da certeza do nosso conhecimento (knowledge) seja os fundamentos daquelas crenças (beliefs) ou opiniões (opinions) tão variadas e diversas que se encontram entre os homens" (CAROTENUTO, 2009, p. 86).

Seus principais conceitos são:

- A experiência é o fundamento de todos os nossos conhecimentos e é de dois tipos: sensação (experiência externa das coisas existentes) e reflexão (experiência interna dos fatos psíquicos);

\footnotetext{
${ }^{32}$ Ibidem, p. 83. Adicionalmente, MENEGHETTI (2010) comenta que "(as mônadas) exercem uma espécie de tensão contínua na qual constroem continuamente a si mesmas, fazendo emergir da própria natureza todas as características que, a cada caso, vêm a assumir; portanto, não é um processo mecânico, mas um contínuo criarse, acrescer, desenvolver de coisas ínsitas na nossa própria natureza" (p. 87).

${ }^{33}$ Ibidem, p. 84.
} 
- A sensação produz ideias de sensações e a reflexão, ideias de reflexões. Todo o conhecimento se origina dessas duas fontes;

- Sentidos e reflexões produzem as ideias simples, ou seja, aquelas ideias que correspondem a qualidades singulares dos objetos ou aos fatos psíquicos singulares;

- As ideias simples constituem o material do conhecimento;

- A ideia a qual damos o nome geral de substância, na realidade, é obscura e confusa, um suporte no qual apoia as qualidades das coisas;

- A experiência permanece o horizonte exclusivo dentro do qual o homem exercita as suas faculdades cognoscitivas e a percepção é a primeira e mais importante faculdade da mente que exercita sobre as ideias: é o momento da reflexão, que unifica a multiplicidade das sensações;

- O intelecto conhece em três modos: 1) intuição, conhecimento imediato, claro e certo que percebe a concordância ou discordância de duas ideias sem a intervenção de outras ideias, 2) demonstração, conhecimento mediado que, raciocinando, através de provas, coliga duas ideias por meio de uma terceira, e 3) sensação, que não atinge a certeza das primeiras duas, mas consente perceber a existência dos entes concretos fora de nós;

- Intuição, demonstração e sensação conduzem, todas as três, a um conhecimento certo e evidente (knowledge), mas segundo uma graduação decrescente: a evidência máxima é dada pela intuição;

- Se o conhecimento se funda na evidência e na certeza, a opinião baseia-se apenas na probabilidade e dá um conhecimento aproximativo garantido, de modo parcial e provisório, pelo acordo da nossa experiência com a experiência dos outros.

- Em síntese, Locke define o conhecimento como "a percepção da concordância ou da discordância entre as nossas ideias" (CAROTENUTO, 2009, p. 87-89).

Se o conhecimento se funda na evidência (nous) e na certeza, a opinião baseia-se apenas na probabilidade e dá um conhecimento aproximativo garantido, de modo parcial e provisório, pelo acordo da nossa experiência com a experiência dos outros (doxa). Incluindose as duas definições distintas, nous e doxa, na premissa de Locke, tem-se como validar a premissa de que o conhecimento sem a evidência é aproximativo, parcial, e não a verdade? (grifo nosso).

Quando Meneghetti (2010) discorre sobre a reimpostação crítica do conhecimento, afirma que:

Da descoberta do critério-base nasce a reimpostação crítica de todo o conhecimento. O homem, em qualquer campo de aplicação que se encontre, deve sempre verificar se o critério está com ele, e se o que está fazendo é coerente à diretiva do próprio critério. Por tal razão, não se tornam prioritárias as verdades, as descobertas dos cientistas, das enciclopédias, dos exploradores, mas somente o que esse critério analisa, confirma e propõe (MENEGHETTI 2010, p. 126).

Nascido cem anos após a morte de Galilei Galilei, Isaac Newton (1642-1727), a despeito de ter sido imortalizado pelo enunciado da Lei da Gravidade, contribuiu decisivamente com a evolução do conhecimento científico no campo filosófico. Reforça a ideia da matematização da pesquisa naturística, insiste na importância da prática experimental e admite ser "inevitável se contentar (em campo físico) com uma elevada probabilidade, 
embora experimentalmente fundada. Dizia, de fato: hypotheses non fingo" (CAROTENUTO, 2009, p. 90) $)^{34}$.

Crítico do aristotelismo, Newton organiza seu método com base em quatro princípios, a saber:

- Simplicidade e uniformidade de natureza;

- O emprego do procedimento analógico em física funda-se na uniformidade da natureza (por exemplo: a luz no fogo doméstico e no sol);

- As propriedades generalizáveis experimentalmente a todos os corpos por analogia (indução) são apenas aquelas estáveis, ou seja, extensão, dureza, impenetrabilidade e massa;

- Os enunciados científicos, se fundados experimentalmente, devem ser considerados verdadeiros mesmo na presença de hipóteses contrárias, enquanto outros experimentos os tornem mais rigorosos ou lhes limite a validade, estabelecendo exceções" (CAROTENUTO, 2009, p. 9-91).

George Berkeley (1685-1753) avança no debate sobre o pensamento empirista e se destaca com a publicação do Ensaio por uma nova teoria da visão (1709) e do Tratado sobre os princípios do conhecimento (1710). Do primeiro, temos:

No entanto, é certo que as ideias recebidas por cada sentido são largamente diferentes e distintas umas das outras. Por serem constantemente observadas juntas, a elas nos referimos como se fossem uma e mesma coisa. Uma das razões disso me parece ser o seguinte: acredita-se que é um grande absurdo imaginar que uma e mesma coisa possa ter mais do que uma extensão ou uma figura. Mas a extensão e a figura de um corpo, sendo introduzidos na mente de duas maneiras e indiferentemente, pela visão ou pelo tato, parece seguir-se que vemos a mesma extensão e a mesma figura que tocamos. Mas se considerarmos as coisas cuidadosamente e mais de perto e, seremos obrigados a reconhecer que nunca vemos e tocamos um único e mesmo objeto. O que é visto é uma coisa e o que é tocado é outra. Se a figura e a extensão visíveis não são o mesmo que as extensões e figuras tangíveis, então não precisamos inferir que uma e mesma coisa tem diversas extensões. A verdadeira consequência é que o objeto da visão e o objeto do tato são duas coisas distintas. Talvez seja necessária alguma reflexão para se conceber corretamente esta distinção. E a dificuldade parece ter aumentado consideravelmente, pois a combinação de ideias visíveis recebe constantemente o mesmo nome da combinação de ideias táteis com as quais ela está conectada, o que resulta necessariamente do uso e fim da linguagem.

Problema de Molyneux: Imagine um homem nascido cego e que, agora adulto, aprendeu a distinguir pelo tato entre um cubo e uma esfera feitas do mesmo material e aproximadamente do mesmo tamanho, de modo a poder dizer, ao tocar um e outro, qual é o cubo e qual é a esfera. Suponha então que o cubo e a esfera sejam colocados sobre uma mesa, e que o homem cego passe a ver. Pergunta-se: poderia ele distinguir e dizer, fazendo uso da visão, antes de tê-los tocado, qual é a esfera e qual é o cubo? Resposta dada: Não. Pois ainda que ele tenha obtido a experiência de como uma esfera e de como um cubo afetam o tato, ele não obteve ainda a experiência de que o que afeta seu tato de tal ou tal maneira deve afetar sua visão de tal ou tal maneira; ou que um ângulo protuberante que pressionou sua mão no cubo de modo desigual deve aparecer aos seus olhos tal como no cubo. Em suma, as ideias da visão são percepções inteiramente novas às quais não há nenhum nome associado em sua mente. Precisamos admitir que não estamos tão sujeitos a

\footnotetext{
${ }^{34}$ Nota do autor: "eu não finjo hipóteses”, “eu não mascaro hipóteses” (tradução nossa).
} 
confundir outros signos com as coisas por eles significadas ou a pensar que sejam da mesma espécie, como o estamos em relação às ideias táteis e as ideias visuais. (...) Quando observamos que os signos são variáveis e produto de instituição humana; quando lembramos que houve um tempo em que eles não estavam conectadas, em nossas mentes, com aquelas coisas que agora tão prontamente sugerem mas que, pelo contrário, sua significação foi aprendida durante os lentos passos da experiência, tudo isso nos previne de confundi-las. Mas quando encontramos os mesmos signos sugerindo as mesmas coisas no mundo inteiro e pensamos que eles não são produto de uma convenção humana; quando não conseguimos lembrar que um dia aprendemos sua significação e acreditamos que, pelo contrário, à primeira vista eles nos teriam sugerido as mesmas coisas que nos sugerem agora; tudo isto nos persuade que eles são da mesma espécie das coisas que cada um representa e que é por semelhança natural que eles as sugerem às nossas mentes. Em suma, penso ser justo concluirmos que os objetos próprios da visão constituem uma linguagem universal do Autor da Natureza, através da qual somos instruídos sobre como regular nossas ações de modo a alcançar aquelas coisas que são necessárias para a preservação e bem-estar de nossos corpos, como também para evitar tudo que possa ser a ele prejudicial e destrutivo. É principalmente através da informação que eles nos fornecem que somos guiados em todos os assuntos e cuidados da vida ${ }^{35}$ (MARÇAL, 2009, p. 108-116).

Do Tratado, de acordo com REALE e ANTISERI (2015, p. 537), extrai-se o título "Primeira parte, na qual indaga-se das principais causas de erro e dificuldade nas ciências e também as bases do ceticismo, do ateísmo e da irreligiosidade”. Avança sustentando Berkeley que:

O nosso conhecimento é conhecimento de ideias e não de fatos" - "é evidente para quem quer que examine os objetos do conhecimento humano que eles são: ideias impressas aos sentidos no momento atual; ideias percebidas atentando para as emoções e os atos da mente; ou, por fim, ideias formadas com a ajuda da memória e da imaginação, reunindo, dividindo ou apenas representando as ideias originariamente recebidas pelos (dois) modos anteriores". "Portanto, os objetos do nosso conhecimento são as ideias" - "é da vista que obtenho as ideias da luz e das cores, com seus vários graus e suas diferenças, com o tato, percebo o duro e o macio, o quente e o frio, o movimento e a resistência etc., tudo isso em quantidade e grau maior ou menor. O olfato me fornece os odores; o gosto me dá sabores; o ouvido transmite à mente os sons, em toda sua variedade de tons e combinações. (...) As ideias, portanto, são sensações. Elas provêm dos sentidos (REALE e ANTISERI, 2015, p. 538).

Berkley (citado por REALE e ANTISERI, 2015), complementa e arremata afirmando

que:

Nós conhecemos somente ideias; elas coincidem com as impressões dos sentidos; as impressões dos sentidos são sempre singulares, ou seja, concretas e individuais; consequentemente, a teoria lockiana da abstração está equivocada; e trata-se de erro grave, pois gera a ilusão de que existem substâncias, essências ou, de todo modo, coisas para além das nossas percepções, como substratos delas (REALE e ANTISERI, 2015, p. 538).

Além dessa infinita variedade de ideias ou de objetos do conhecimento, há ainda algo que conhece ou percebe essas ideias, exercendo sobre elas diversos atos, como

\footnotetext{
${ }^{35}$ Grifo nosso.
} 
o querer, o imaginar, o recordar etc. Esse ser que percebe e age é aquilo a que chamo 'mente', 'espírito', 'alma', 'eu'. Com essas palavras não indico nenhuma ideia minha, mas coisa diferente de todas as minhas ideias e na qual elas existem, ou seja, pela qual elas são percebidas, o que significa a mesma coisa, pois a existência de uma ideia consiste em ser percebida" (...) "Todos devem reconhecer que nem os nossos pensamentos, nem os nossos sentimentos, nem as ideias formadas pela imaginação podem existir sem a mente. Mas, para mim, não é menos evidente que as várias sensações, ou seja, as ideias impressas aos sentidos, por mais fundidas e combinadas estejam (ou seja, quaisquer sejam os objetos compostos por elas), não podem existir senão em uma mente que as percebe" (ibid., p. 544).

Eis a raiz do princípio defendido por Berkeley, Esse est percipi (“o ser é o ser percebido", em tradução livre).

Antonio Meneghetti (1936-2013), afirma que "é verdade somente o que pode ser verificado empiricamente por meio dos sentidos" ${ }^{36}$ (2010, p. 86), e evolui defendendo que "aquilo que o homem percebe, inclusive a si mesmo - é uma zona, uma parte, uma fenomenologia do ser que ê,37.

Eis aqui um momento crucial da contribuição única da Ciência Ontopsicológica à compreensão do conhecimento humano, o ponto-chave. Explica Meneghetti (2011):

\begin{abstract}
“O ponto-chave é a evidência. Quanto qualquer categoria, discussão, parâmetro, aplicação é certificada, é demonstrada, é o ponto invariável da realidade, tem o reconhecimento através da entidade da evidência. Evidência significa: o objeto em si e o visto pelo sujeito (ex vidente) coincidem (pelo vidente e o que o vidente vê, o ser é unívoco), reversibilidade de um idêntico (modos diversos, fenomenologias diversas, mas ao final retorna-se no idêntico: o idêntico do sujeito é o idêntico do objeto). Imagem e fato são reversíveis. A evidência é a unidade entre objeto e sujeito, a unidade que envera um no outro, porque revela a identidade do ser. É mais importante o objeto ou o sujeito? Se nos colocamos diante do em si do mundo-davida, da realidade, nós vivemos pouco tempo, os objetos, os outros continuarão. Porém, nesse momento, sou eu que faço filosofia, pesquisa, portanto, a importância da solução é nevrálgica porque $e u$ estou em problema, portanto $e u$ devo saber, compreender, resolver, e então para mim que estou dentro do problema - ser ou não ser - eu, que sou o ponente do problema, sou o mais importante na solução do problema. Nesse sentido, é mais importante o sujeito, enquanto sou eu ponente objetificado pelo problema. O ser é sempre, que eu exista ou não. Conclusão: dessa evidência compreendo que eu sou por quanto e como percebo, ajo, sou contato. Eu sou e sou relação a, e a coisa que é em relação a mim é junto comigo. Eis o conceito de esse est percipi do filósofo Berkeley. A percepção revela a identidade do ser em mim sujeito e na percepção do objeto. Eu conheço o ser por como e quanto o percebo, não posso superar, transcender, anular. Eu mesmo: tudo se convalida a partir do Eu sou, da ecceidade do meu único e irrepetível modo de existir (MENEGHETTI, 2011, p. 36-37).
\end{abstract}

Até aqui avançamos muito e alcançamos um novo estágio da evolução das teorias do conhecimento. Novamente, temos a convicção de ter coberto inúmeras variáveis, apontado

\footnotetext{
${ }^{36}$ MENEGHETTI, Antonio. Manual de Ontopsicologia. 4. ed. Recanto Maestro: Ontopsicológica Editora Universitária, 2010.

${ }^{37}$ MENEGHETTI, Antonio. Da consciência ao ser. Como impostar a Filosofia do futuro. Recanto Maestro:

Ontopsicológica Editora Universitária, 2014b. p. 192.
} 
diversas contribuições e elencado incontáveis informações acerca da grande contribuição do Humanismo Histórico e do Empirismo à compreensão do ser humano e acerca do conhecimento do ser humano, mas, certamente, não deixando de pontuar a contribuição da Ciência Ontopsicológica em absoluto e imprescindível complemento a séculos de história para o entendimento do homem protagonista da vida. Novos artigos haverão de ser escritos para a continuidade de nosso estudo [e compreensão].

\section{Considerações Finais}

A propósito da evolução do pensamento filosófico humanista, e sua inegável contribuição ao conhecimento humano, permanecemos atentos à prevalência da opinião (doxa) sobre a ciência (episteme). Buscando inspiração no "homem renascentista", "criativo", "centro do mundo", retomamos a busca da verdade científica. Como? Da letra de Antonio Meneghetti (2010), destacamos:

\footnotetext{
"A Ontopsicologia é um método para autenticar e desenvolver o homem criativo, mas para obter isso é preciso saber ler a última positividade da natureza humana. Dentro do inconsciente de cada homem, já existe uma estrada de inteligência, o modo no qual realizar-se. A inteligência da vida tem o poder para chegar ao máximo. Todas as doenças, de qualquer gênero, indicam sempre um erro de comportamento contra a natureza. Religiões, culturas, pontos de vista, afetos garantem ao indivíduo um álibi existencial, mas o veredicto da inteligência de natureza não conhece o perdão ou a boa fé. $\mathrm{O}$ nosso inconsciente tem uma exatidão implacável. Nós, seres humanos, viemos de quem sabe quantos milênios, da eternidade, e não podemos estar atrás de ideias de costume, de moral, ideias bolchevistas, italianas ou católicas, etc.” (MENEGHETTI, 2010, p. 282-283).
}

Deste modo, resta clara a importância do estudo da Cultura Clássica e da Cultura Humanista de forma categórica no intuito de compreender, eventualmente contrapor, estudar, discutir, (inter)relacionar, mas acima de tudo verificar as contribuições, a cada um dos autores supramencionados, que a ótica de análise da Ciência Ontopsicológica pode dar.

\section{Referências}

ABBAGNANO, Nicola. Dicionário de Filosofia. São Paulo: Martins Fontes, 2012.

FERREIRA, Auréiio Buarque de Holanda. Dicionário Aurélio da Língua Portuguesa. 5. ed. São Paulo: Editora Positivo, 2010. 
CAROTENUTO, Margherita. Histórico sobre as teorias do conhecimento. Recanto Maestro: Ontopsicológica Editora Universitária, 2009.

MARÇAL, Jairo (Org.). Antologia de Textos Filosóficos. Curitiba, Paraná: Secretaria de Educação do Estado do Paraná, 2009. Disponível em:

$<$ http://www.educadores.diaadia.pr.gov.br/arquivos/File/cadernos_pedagogicos/caderno_filo. pdf $>$

MENEGHETTI, Antonio. Dicionário de Ontopsicologia. 2. ed. Recanto Maestro: Ontopsicológica Editora Universitária, 2008.

MENEGHETTI, Antonio. Manual de Ontopsicologia. 4. ed. Recanto Maestro: Ontopsicológica Editora Universitária, 2010.

MENEGHETTI, Antonio. Conhecimento ontológico e consciência. Recanto Maestro: Ontopsicológica Editora Universitária, 2011.

MENEGHETTI, Antonio. Do Humanismo Histórico ao Humanismo Perene. Recanto Maestro: Ontopsicológica Editora Universitária, 2014a.

MENEGHETTI, Antonio. Da consciência ao ser. Recanto Maestro: Ontopsicológica Editora Universitária, 2014b.

REALE, Giovanni; ANTISERI, Dario. História da Filosofia. Patrística e Escolástica. Volume 2. São Paulo: Paulus, 2015. 